Erratum

\title{
Aktuelle Standards in der Therapie des Magenkarzinoms
}

Im Beitrag „Aktuelle Standards in der Med Wochenschr 2015; 140: 1202-1205)

Therapie des Magenkarzinoms“ (Dtsch muss es in Tabelle 1 korrekt lauten:

Fuchs et al. Ramucirumab 5,2 Mon vs. Verbesserte Symptomkontrolle,

[14] vs. Placebo 3,8 Mon längere Stabilisierung der

$(\mathbf{n}=355)$ REGARD $\quad(p=0,044) \quad$ Lebensqualität 